\title{
Cuban zeolite for lead sorption: application for water decontamination and metal quantification in water using nondestructive techniques
}

\author{
Y. Enamorado-Horrutiner ${ }^{1}$ - M. E. Villanueva-Tagle ${ }^{2} \cdot$ M. Behar ${ }^{3}$. \\ G. Rodríguez-Fuentes ${ }^{4}$ J. Ferraz Dias $^{3} \cdot$ M. S. Pomares-Alfonso ${ }^{5}$
}

Received: 27 May 2015/Revised: 10 December 2015/ Accepted: 9 February 2016/Published online: 9 March 2016

(C) Islamic Azad University (IAU) 2016

\begin{abstract}
In the present paper, a Cuban clinoptilolite-type zeolite was used as lead sorbent. The effect of chemical conditioning with $1 \mathrm{~mol} \mathrm{~L}^{-1} \mathrm{NaCl}, \mathrm{NaOH}$ and $\mathrm{NH}_{3}$ solutions at room temperature on the ion exchange capacity for lead uptake by clinoptilolite has been investigated. According to the batch experiments, $\mathrm{NH}_{3}$-treated clinoptilolite exhibited the highest sorption capacity. For this material, the effect that contact time, solid-to-liquid ratio and $\mathrm{pH}$ have on the removal of lead from aqueous solutions was comprehensively analyzed, and the most suitable values for these parameters were selected afterward. The pseudo-second-order kinetic model was appropriate for the description of the kinetic performance of the sorption. The
\end{abstract}

Electronic supplementary material The online version of this article (doi:10.1007/s13762-016-0956-9) contains supplementary material, which is available to authorized users.

M. S. Pomares-Alfonso

mpomares@imre.oc.uh.cu

1 Departamento de Química Analítica, Facultad de Química, Universidad de la Habana, Zapata y G, El Vedado, CP 10400 Havana, Cuba

2 Departamento de Química General, Facultad de Química, Universidad de la Habana, Zapata y G, El Vedado, CP 10400 Havana, Cuba

3 Laboratório de Implantação Iônica, Instituto de Física, Universidade Federal do Rio Grande do Sul, UFRGS, Porto Alegre, RS, Brazil

4 Laboratorio de Ingeniería de Zeolitas, Instituto de Ciencia y Tecnología de Materiales, Universidad de la Habana, Zapata y G s/n, Vedado, CP 10400 Havana, Cuba

5 Laboratorio Universitario de Composición y Estructura de la Sustancia, Instituto de Ciencia y Tecnología de Materiales, Universidad de la Habana, Zapata y G, El Vedado, CP 10400 Havana, Cuba
Langmuir and Freundlich isotherm models were applied to describe sorption process, and the best fit was reached by using the Freundlich model. The nondestructive techniques, namely particle-induced X-ray emission and X-ray fluorescence, have successfully been evaluated for determining lead concentration in water by its concentration in zeolite. In addition, the more traditional flame atomic absorption spectrometry determination of lead in water was also improved.

Keywords Lead determination - Kinetic modeling . Sorbent material $\cdot$ Particle-induced X-ray emission $\cdot \mathrm{X}$-ray fluorescence

\section{Introduction}

Industrial activities and other human actions have caused the concentration of several toxic metals such as lead, copper, cadmium, mercury, arsenic, zinc, among others, to be increase in natural water (Alfaro de la Torre and Tessier 1993). In this threatening context, scientists from different research areas have performed quite an extensive investigation in order to obtain more efficient methodologies (a) to control the metal concentration in water and/or (b) remove metals from it. In both cases, it is crucial that selected materials are able to capture target metals efficiently.

Over the past years, natural zeolite has frequently been used as sorbent material due to its chemical and physical properties, which favor the retention of different substances, including metals. Particularly, clinoptilolite-type zeolite has been used successfully for removing lead from contaminated water (Bailey et al. 1999; Inglezakis et al. 1999; Inglezakis et al. 2002, 2003; Babel and Kurniawan 
2003; Ramos et al. 2004; Sprynskyy et al. 2006; Castaldi et al. 2008; Wang and Peng 2010; Misaelides 2011; Kragovic et al. 2012). More recently, sorption of lead and other heavy metals in natural and Fe(III)-modified zeolite has been reported (Kragovic et al. 2013a, b; Sirotiak et al. 2015)

Solution $\mathrm{pH}$, contact time between sorbent and solution and the concentration of metals in solution and sorbent mass-to-volume solution ratio are important parameters that can heavily influence the lead sorption capacity of zeolite. However, in some reports, not all parameters have been taken into consideration, and, in other cases, the values used for these parameters were not experimentally justified. See, for example, the results reported by Inglezakis et al. (2002, 2003) and Kragovic et al. (2012).

In most reviewed researches, sorption experiments are preferably performed at room temperature because their operational costs increase considerably if they are carried out at higher temperatures (Malamis and Katsou 2013). However, some studies have been conducted at temperatures up to $60{ }^{\circ} \mathrm{C}$ (Inglezakis et al. 2004, 2007; Karatas 2012; Kragovic et al. 2013a, b).

In general, natural zeolites are chemically treated in order to increase the sorption of metal ions. $\mathrm{NH}_{4} \mathrm{Cl}, \mathrm{NaCl}$ and $\mathrm{NaOH}$ solutions at temperatures ranging from room temperature up to $90{ }^{\circ} \mathrm{C}$ are used the most (Inglezakis et al. 1999, 2001; Ramos et al. 2004; Malamis and Katsou 2013). For example, Ramos et al. (2004) studied, in two different experiments, the effect of chemical treatments of clinoptilolite-type zeolite with $\mathrm{NH}_{4} \mathrm{Cl}$ solution, in one experiment, and $\mathrm{NaCl}$ solution, in the other one, both with a concentration of $2 \mathrm{~mol} \mathrm{~L}^{-1}$. Those treatments were repeated several times at $90{ }^{\circ} \mathrm{C}$ during $12 \mathrm{~h}$ for up to 7 days. In another work (Inglezakis et al. 1999), the chemical treatment with $1 \mathrm{~mol} \mathrm{~L}^{-1} \mathrm{NaCl}$ at $70^{\circ} \mathrm{C}$ with periodic $(24 \mathrm{~h})$ renewal of the solution was given for 10 days. In a comparative study, Inglezakis et al. (2001) monitored the modifying action of $\mathrm{NaCl}, \mathrm{NaOH}$ and $\mathrm{HNO}_{3}$ on zeolite. However, studies of the sorption of lead on clinoptilolite-type zeolite treated with $\mathrm{NH}_{3}$ have not been conducted yet.

In most reports, zeolite has been used for remediation purposes. The use of zeolite as sorbent material for separation/concentration of metals prior to quantification has been scarcely studied (Granda et al. 2006). Zeolites of the clinoptilolite type were used for separation and pre-concentration of arsenite and arsenate from natural water prior to instrumental determination of arsenic (González et al. 2001). In another work, Pérez et al. (2008) used a surfactant-modified zeolite (SMZ) (clinoptilolite) for chromium speciation.
Flame atomic absorption spectrometry (FAAS) (Inglezakis et al. 1999, 2002, 2003, Ramos et al. 2004) and inductively coupled plasma optical emission spectrometry (ICP-OES) (Ramos et al. 2004; Castaldi et al. 2008) have been used as detection techniques in reviewed studies of the sorption of metals on zeolites. It is a well-known fact that these techniques are very easily applied for the direct analysis of samples in liquid state. However, in sorption studies where solid sorbent materials are employed there is the need for metals to be eluted from sorbent material first, and then, metals can be quantified by FAAS or ICP-OES in eluted solutions. Instead of elution, sorbent material could be digested. But digestion of samples increases the risk of samples becoming contaminated, part of analytes getting lost, and error of analysis, which can certainly make quantification of metals somewhat difficult.

In this context, the direct analysis of sorbent materials by using other techniques, such as particle-induced X-ray emission (PIXE) and X-ray fluorescence (XRF), is certainly very useful. It is a well-known fact that the preparation of solid samples for the analysis by PIXE (Hernández García et al. 2012) and XRF (Kolbe and Hönicke 2015; Daar et al. 2015; Ghosh et al. 2015) is much simpler than by FAAS and ICP-OES, and most difficulties associated with digestion of samples are overcome. Moreover, when PIXE and XRF are used, samples are hardly consumed or deteriorated, which allows them to be analyzed by other techniques. Surprisingly few and relatively old reports on determination of metals in zeolites by XRF with different purposes were found (Willis 1988, Pillay and Peisach 1991; Boza et al. 2001). Interestingly enough, the use of the PIXE technique has been reported only for the analysis of $\mathrm{Si} / \mathrm{Al}$ ratio in zeolitic materials so far (Willis 1988, Pillay et al. 1990; Pillay and Peisach 1991).

Consequently, the present work is aimed at studying and selecting the experimental chemical and physical conditions for a good sorption of lead present in water on a Cuban-treated clinoptilolite-type zeolite. Thereafter, the use of zeolite in order to concentrate lead from water and further quantification of sorbed lead by PIXE and XRF techniques is explored as alternative detection techniques. In addition, the more traditional FAAS technique is also employed for quantification after lead concentration in zeolite.

This work was carried out from 2013 to 2014. The experiments were performed at the Institute of Science and Technology of Materials (IMRE, according to its abbreviation in Spanish) of the University of Havana and the Ion Implantation Laboratory of the Universidade Federal do Rio Grande do Sul, Porto Alegre, Brazil. 


\section{Materials and methods}

\section{Reagents, solutions and sorbent material}

Pure reagents for analysis (pure for analysis, PA) were used: $65 \% \mathrm{HNO}_{3}$ (Panreac, Spain), $\mathrm{NaCl}$ (Riedel-de Haen, Germany), $\mathrm{NaOH}$ (Fluka, Germany) and $25 \% \mathrm{NH}_{3}$ (UNICHEM, China). Calibration solutions were prepared from $1000 \mathrm{mg} \mathrm{L}^{-1} \mathrm{~Pb}$ standard solution (Spectrosol, BDH, England) by dilution in $1 \% \mathrm{v} / \mathrm{v} \mathrm{HNO}_{3}$. Ultra-pure water from a double distiller (Aquatron A4D, Germany) was used.

Purified and homogenized zeolite, obtained by Rodríguez Fuentes et al. (2000) as a result of the processing of the raw mineral zeolite from the deposit Tasajeras, Cuba, was used as sorbent material. The major mineral phase of this zeolite is the clinoptilolite. Zeolite used in the present work is called as $\mathrm{NZ}$ zeolite. NZ zeolite was screened (particles $<3 \mathrm{~mm}$ in diameter) and chemically treated afterward in three different experiments with $\mathrm{NaCl}, \mathrm{NaOH}$ and $\mathrm{NH}_{3}$ solutions, respectively, with a concentration of $1 \mathrm{~mol} \mathrm{~L}^{-1}$ and at room temperature in order to obtain three other products called in this work $\mathrm{NaCl}$-, $\mathrm{NaOH}$ - and $\mathrm{NH}_{3}$-treated $\mathrm{NZ}$ zeolites, respectively. Ways of chemically treating NZ zeolite were found in the literature (Granados et al. 2000).

\section{General procedure followed in the sorption study}

A portion of sorbent material was put into a solution of lead with a known concentration and shaken by using a magnetic shaker. Immediately after, it was filtered by a Whatman filter paper, Grade 40, and the remaining solution was analyzed by FAAS to determine the concentration of lead. Solid sorbent mass-to-volume solution ratio and lead concentration in solution were studied in the range of 0.06-10 and 1-150 $\mathrm{mg} \mathrm{L}^{-1}$, respectively. Lead solution $\mathrm{pH}$ adjustment was carried out using nitric acid and $\mathrm{NaOH}$ solutions.

Sorption capacity was calculated by Eq. 1

$q=\frac{V\left(C_{\mathrm{i}}-C_{\mathrm{f}}\right)}{m}$

where $V$ is lead solution volume; $C_{\mathrm{i}}$ is initial concentration of lead in solution (before sorption process); $C_{\mathrm{f}}$ is lead concentration determined in remaining solution (after sorption process); and $m$ is sorbent mass. All the sorption experiments were replicated three times. Average sorption capacity and standard deviation were calculated afterward.

\section{Equipments}

In the study of the sorption process, FAAS was used for the determination of lead in solution. It was also used in a specific experiment in order to demonstrate the potential of treated NZ zeolite to concentrate lead in water prior to quantification by FAAS, under routine instrumental operating conditions, in eluted solution. Additionally, lead content was determined by using PIXE and XRF techniques in solid samples (sorbent zeolitic materials) after and before the sorption process. Operating instrumental conditions of both techniques are given in the corresponding section.

The powder X-ray diffraction (XRD) technique was applied to zeolitic materials in order to evaluate possible mineralogical and structural changes of the samples after chemical treatments. A SHIMADZU XRD 7000 diffractometer $(\mathrm{Cu} \mathrm{K} \alpha)$ was used. The X-ray generator operated at $30 \mathrm{kV}, 30 \mathrm{~mA}$. The goniometer was equipped with a graphite monochromator in the diffracted beam. The patterns were collected in the angular range from $10^{\circ}$ to $80^{\circ}$ with $0.02^{\circ}$ of step size. The FullProf program for Rietveld analysis of powder patterns was run.

\section{Statistical data analysis}

In the kinetic and isothermal adsorption studies, it was evaluated how well theoretical models fitted to experimental data, by using the lack-of-fit statistical test, with confidence level being 95 or $99 \%$, according to the specific case. The effect that chemical treatments of zeolite have on lead sorption capacity was statistically evaluated by using the two-way analysis of variance (two-way ANOVA), with confidence level being 95 or $99 \%$. Thus, the mean differences between groups that were split on two independent variables, treatment and lead concentration, were evaluated. Details about ANOVA and lack-of-fit statistical tests applied can be found in Draper and Smith (1981).

\section{Results and discussion}

\section{Effect of chemical treatments of zeolite on its sorption capacity for lead: equilibrium study}

The equilibrium relationship between the amount of lead on the sorbent material and the amount of lead in solution was studied for NZ zeolite and for the three NZ zeolites chemically treated with $\mathrm{NaOH}, \mathrm{NaCl}$ and $\mathrm{NH}_{3}$, respectively. In this experiment, solutions were prepared with different lead concentrations ranging from 1 to $150 \mathrm{mg}$ $\mathrm{L}^{-1}$. For non-treated and $\mathrm{NaOH}$-treated $\mathrm{NZ}$ zeolite, the essays were performed with initial concentrations from 1 to $50 \mathrm{mg} \mathrm{L^{-1 }}$ because saturation of sorbent material was reached for $25 \mathrm{mg} \mathrm{L}^{-1}$. Because of similar reasons, essays were performed from 1 to $100 \mathrm{mg} \mathrm{L}^{-1}$ and from 1 to 
$150 \mathrm{mg} \mathrm{\textrm {L } ^ { - 1 }}$ for $\mathrm{NaCl}$ - and $\mathrm{NH}_{3}$-treated $\mathrm{NZ}$ zeolite, respectively. In all cases, other parameters were fixed as follows: sorbent mass of $10 \mathrm{mg}$, lead solution volume of $10 \mathrm{~mL}, \mathrm{pH}$ of 5 , contact time of $1 \mathrm{~h}$ and room temperature. According to the aims of the present work, the sorbent mass and solution volume were reasonably low as it is usual in analytical methodologies. On the other hand, $\mathrm{pH}$ of solution of 5 was selected, according to previous experiences (Ponizovskya and Tsadilas 2003). The mean sorption capacity $(n=3)$ and absolute standard deviation for treated and non-treated zeolites and for each concentration of lead in solution are represented in Fig. 1. In addition, all data of Fig. 1 are also provided in Table $1 \mathrm{~S}$ of the Supplementary Material.

Sorption capacity $(q)$ generally tends to enhance as concentration of lead does, from 1 to $150 \mathrm{mg} \mathrm{L}^{-1}$. This general tendency seems to be quite similar for chemically treated and non-treated NZ zeolites. On closer examination, however, different behaviors of $q$ can be observed. For a lead concentration ranging from 1 to $10 \mathrm{mg} \mathrm{L}^{-1}$, the sorption capacity of zeolite was not significantly changed by chemical treatments within the experimental error, according to ANOVA ( $n=3, \alpha=0.05)$. Besides, sorption capacity of all materials continuously increased with the increment of lead concentration in solution. When lead concentration increased from 20 to $150 \mathrm{mg} \mathrm{L}^{-1}$, different behaviors of the sorption capacity $(q)$ for lead were observed, according to the specific material. Saturation of non-treated and NaCl-treated NZ zeolite was observed for $25 \mathrm{mg} \mathrm{L}^{-1}$ of lead. In contrast, saturation of $\mathrm{NaOH}$ - and $\mathrm{NH}_{3}$-treated zeolite was reached for concentrations of 75 and $100 \mathrm{mg} \mathrm{L}^{-1}$, respectively.

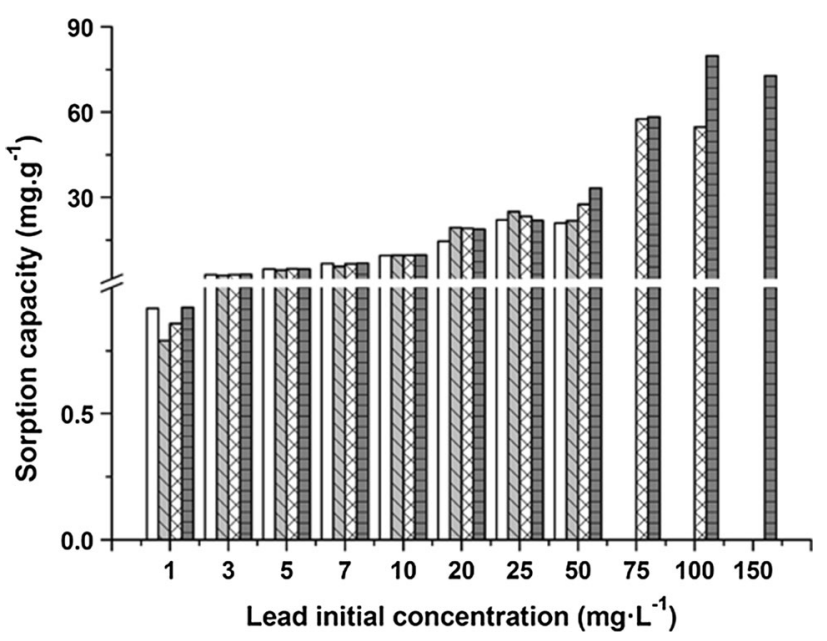

Fig. 1 Variation of lead sorption capacity $(q)$ of NZ zeolite ( $\square$ ), $\mathrm{NaOH}$-treated zeolite (口), NaCl-treated zeolite $(\bigotimes)$ and $\mathrm{NH}_{3}$-treated zeolite $(\square)$ for different concentrations of lead in solution
The variability of lead capture, given as the relative standard deviation (RSD) of the sorption capacity, depended also with lead concentration in solution. For concentrations ranging from 1 to $10 \mathrm{mg} \mathrm{L}^{-1}$, quite low variability (3-10\%) was observed. However, variability increased between 7 and $40 \%$ in concentrations of lead higher than $10 \mathrm{mg} \mathrm{L}^{-1}$.

According to the obtained results, the highest lead sorption capacity of $80 \pm 9 \mathrm{mg} \mathrm{g}^{-1}$ was achieved by $\mathrm{NH}_{3^{-}}$ treated NZ zeolite.

From a theoretical point of view, the Langmuir and Freundlich models are the most frequently used isotherms in sorption studies (Malamis and Katsou 2013), and both were evaluated in the present work. In conformity with the lack-of-fit statistical test at the $95 \%$ confidence level, the Langmuir model did not fit to the experimental data. For that reason, regression parameters of Langmuir model are not shown. On the contrary, a good fit was obtained by using the Freundlich model for non-treated and chemically treated NZ zeolites. This model is expressed by the following Eq. 2 (Freundlich 1906):

$q_{\mathrm{e}}=K_{\mathrm{F}} C_{\mathrm{e}}^{1 / n}$

Or by the corresponding linear expression 3 (Hamidpour et al. 2011):

$\log q_{\mathrm{e}}=\log K_{\mathrm{F}}+\frac{1}{n} \log C_{\mathrm{e}}$

where $q_{\mathrm{e}}$ is the amount of sorbed lead per unit mass of sorbent $\left(\mathrm{mg} \mathrm{g}^{-1}\right)$ and $C_{e}$ is the equilibrium concentration of lead in solution $\left(\mathrm{mg} \mathrm{L}^{-1}\right) . K_{\mathrm{F}}\left(\mathrm{mg} \mathrm{g}^{-1}\right)$, the Freundlich isotherm constant is an approximate indicator for adsorption capacity and $\mathrm{n}$ is related to the adsorption intensity. $K_{\mathrm{F}}$ and $n$ are characteristics of the sorbentsorbed system.

The regression parameters of the Freundlich isotherm for the four sorbent materials under study are given in Table 1. The good correlation coefficients (from 0.9977 to 0.9995), and, principally, the adequacy of the theoretical model to the experimental data, according to the lack-of-fit statistical test, allow to describe the lead sorption process in the studied system by a Freundlich isotherm. Consequently, the sorption of lead on NZ zeolite was characterized by a typical multi-site adsorption isotherm for heterogeneous surfaces. The highest value of $K_{\mathrm{F}}$ (1.00 \pm 0.01$)$ calculated for $\mathrm{NH}_{3}$-treated $\mathrm{NZ}$ zeolite from the adjusted model is in good agreement with the highest sorption capacity of this material obtained experimentally. On the other hand, the sorption intensity $\mathrm{n}$ was higher than one for $\mathrm{NH}_{3}$-treated $(n=1.05 \pm 0.01)$ and $\mathrm{NaCl}$-treated $(n=1.02 \pm 0.01) \mathrm{NZ}$ zeolite which indicated a favorable sorption process for both materials (Goldberg 2005). Nevertheless, as pointed out earlier, the highest 
Table 1 Average \pm standard deviation of regression parameters of the Freundlich adsorption isotherm and regression coefficient

\begin{tabular}{llll}
\hline Sorbent material & $\begin{array}{l}\text { Freundlich isotherm } \\
\text { constant }\left(K_{\mathrm{F}}\right)(\mathrm{mg} / \mathrm{g})\end{array}$ & $\begin{array}{l}\text { Adsorption } \\
\text { intensity }(n)\end{array}$ & $\begin{array}{l}\text { Regression } \\
\text { coefficient }\left(R^{2}\right)\end{array}$ \\
\hline Non-treated NZ zeolite & $0.91 \pm 0.01$ & $0.98 \pm 0.01$ & 0.9989 \\
$\mathrm{NH}_{3}$-treated NZ zeolite & $1.00 \pm 0.01$ & $1.05 \pm 0.01$ & 0.9988 \\
$\mathrm{NaOH}$-treated NZ zeolite & $0.75 \pm 0.01$ & $0.92 \pm 0.01$ & 0.9995 \\
$\mathrm{NaCl}$-treated NZ zeolite & $0.93 \pm 0.01$ & $1.02 \pm 0.01$ & 0.9977 \\
\hline
\end{tabular}

experimental sorption capacity was obtained for $\mathrm{NH}_{3}-$ treated NZ zeolite.

In order to find out the reasons for enhanced lead sorption capacity of $\mathrm{NH}_{3}$-treated $\mathrm{NZ}$ zeolite, mineral phases of non-treated and treated zeolites powder samples were studied by XRD analysis. X-ray diffraction patterns for $\mathrm{NH}_{3^{-}}$and $\mathrm{NaCl}$-treated zeolites were similar, and therefore, only the first one is shown in Fig. 2 along with the $\mathrm{NaOH}$ - and non-treated $\mathrm{NZ}$ zeolites patterns. The major mineral phases identified in all the studied materials were clinoptilolite-heulandite according to the (200) and (131) signals at $2 \theta=11.12^{\circ}$ and $22.33^{\circ}$, respectively, and quartz, identified by the main (101) signal at $2 \theta=26.40^{\circ}$. This result agrees with previous ones reported for purified NZ zeolite (Rodríguez et al. 1998) and raw zeolite from the deposit Tasajeras (Baerlocher et al. 2001). Basically, the diffraction signals of the major mineral phases of treated and non-treated NZ zeolites maintained similar shape and intensity, which suggested that the structure of zeolite was not modified by chemical treatments. However, the presence of an additional signal at $2 \theta=29.48^{\circ}$ in the diffraction pattern of $\mathrm{NaOH}$-treated $\mathrm{NZ}$ zeolite suggested the formation of the new crystalline phase called $\mathrm{P}$ zeolite. This phase was also observed after the hydrothermal

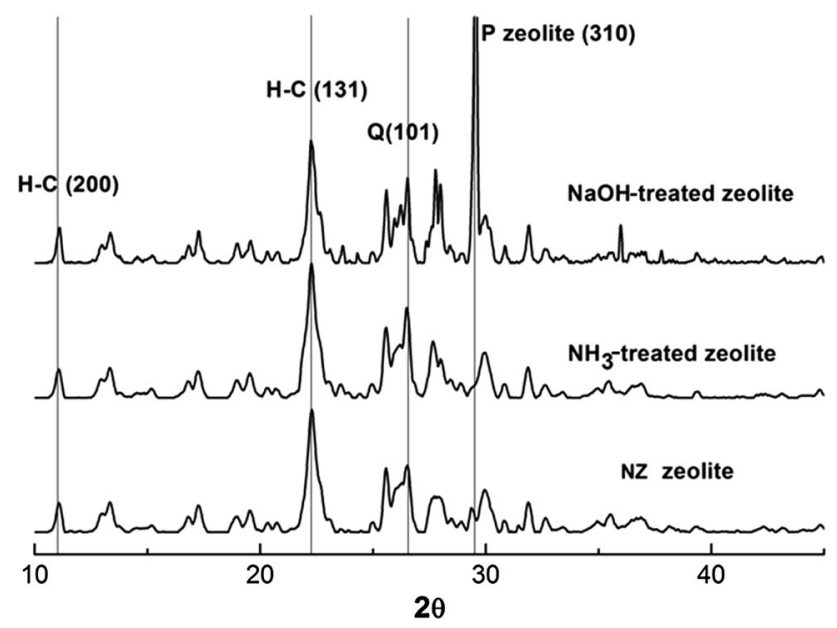

Fig. 2 Heulandite-clinoptilolite $(\mathrm{H}-\mathrm{C})$ and quartz $(\mathrm{Q})$ phases in the $\mathrm{X}$-ray diffraction patterns of the non-treated, $\mathrm{NaOH}$ - and $\mathrm{NH}_{3}$-treated NZ zeolite treatment of NZ zeolite in the presence of sodium silicate (Rodríguez et al. 2004). Interestingly enough, the $\mathrm{P}$ zeolite phase emerged as a result of a soft treatment at room temperature. Yet, the enhanced lead sorption capacity of $\mathrm{NH}_{3}$-treated $\mathrm{NZ}$ zeolite was not associated with this phase. The $\mathrm{NH}_{4}{ }^{+}$ions present in the $\mathrm{NH}_{3}$ aqueous solution are able to exchange a significant part of natural cations in clinoptilolite-type zeolite, mainly $\mathrm{Ca}^{2+}$, favoring the sorption of $\mathrm{Pb}^{2+}$. A more comprehensive explanation of the observed effect was beyond the reach of the present work and requires the design and performance of additional experiments.

After the enhanced lead sorption capacity of $\mathrm{NH}_{3}$-treated NZ zeolite was demonstrated, the possible effect of the other operating parameters such as acidity of solution, contact time and solid-to-liquid ratio on the lead sorption capacity was study in order to select appropriate operational conditions.

\section{Effect of pH of lead solution}

The $\mathrm{pH}$ of an aqueous solution is a parameter being of great importance for metals to be captured by zeolite because $\mathrm{pH}$ influences the charge and quantity of sites on surfaces of materials, interaction between mineral and metal ions, and solution chemistry of heavy metals (Hamidpour et al. 2011). Therefore, the effect of $\mathrm{pH}$ on sorption of lead on $\mathrm{NH}_{3}$-treated zeolite was investigated, with $\mathrm{pH}$ values ranging from 3 to 7 (Fig. 3).

Four solutions were used to adjust $\mathrm{pH}$. The 1.0 and $0.1 \mathrm{~mol} \mathrm{~L}^{-1} \mathrm{NaOH}$ solutions were prepared with $\mathrm{NaOH}$ powder reagent (Fluka, Germany), whereas 1.0 and $0.1 \mathrm{~mol} \mathrm{~L}^{-1} \mathrm{HNO}_{3}$ solutions were prepared with $65 \% \mathrm{PA}$ nitric acid (Panreac, Spain). The other parameters fixed in this experiment were sorbent mass of $10 \mathrm{mg}$, lead solution volume of $10 \mathrm{~mL}$, lead concentration in solution of $5 \mathrm{mg}$ $\mathrm{L}^{-1}$, contact time of $1.0 \mathrm{~h}$ at room temperature, with a magnetic shaker being used.

As observed in Fig. 3, the lead sorption capacity was approximately the same for $\mathrm{pH}$ range 4-7, with it decreasing for $\mathrm{pH}$ of 3 . It has been proven that some of the $\mathrm{Pb}$ (II) species in aqueous solution are $\mathrm{Pb}^{2+}, \mathrm{Pb}(\mathrm{OH})^{+}$, $\mathrm{Pb}(\mathrm{OH})_{2}, \mathrm{~Pb}(\mathrm{OH})_{3}^{-}, \mathrm{Pb}(\mathrm{OH})_{4}^{2-}, \mathrm{Pb}_{4}(\mathrm{OH})_{4}^{4+}, \mathrm{Pb}_{2}(\mathrm{OH})^{3+}$ 


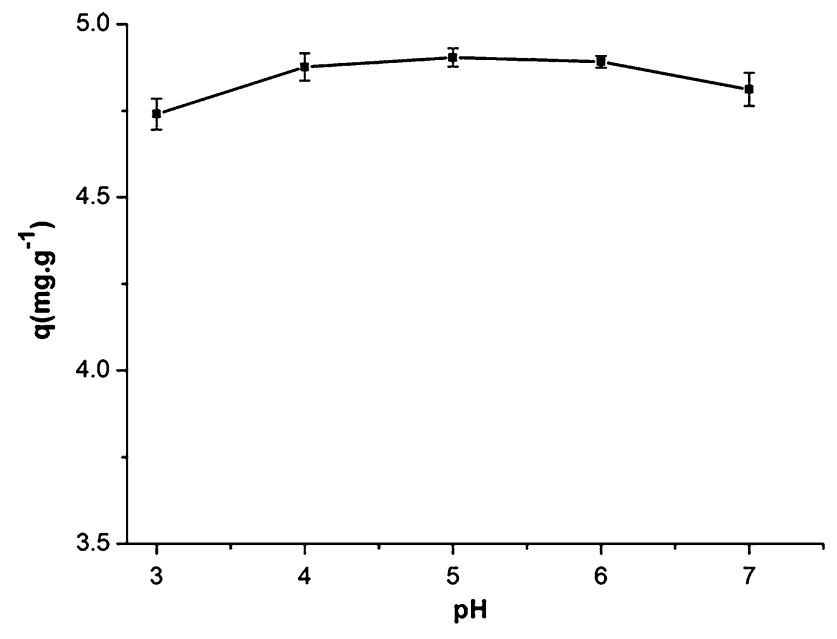

Fig. 3 Variation of the lead sorption capacity $(q)$ of $\mathrm{NH}_{3}$-treated zeolite with $\mathrm{pH}$ of the solution

and $\mathrm{Pb}_{3}(\mathrm{OH})_{4}^{2+}$ (Hamidpour et al. 2011; Karatas 2012). Under acidic conditions, the predominant $\mathrm{Pb}$ (II) species is $\mathrm{Pb}^{2+}$, whereas $\mathrm{Pb}(\mathrm{OH})_{2}$ (solid) is present with higher $\mathrm{pH}$ values. Therefore, the lower sorption of metal ions with $\mathrm{pH}$ being of 3 was probably due to the presence of an excess of $\mathrm{H}^{+}$ions in the solution, which competed with the predominant $\mathrm{Pb}^{2+}$ species for the sorption sites. With $\mathrm{pH}$ values increasing from 4 to 7 , the zeolite surfaces became negatively charged favoring sorption of lead species (Sprynskyy et al. 2006; Hamidpour et al. 2011; Karatas 2012). Based on the experimental results, it can be concluded that $\mathrm{pH}$ of the solution has to range from 4 to 7 , with there being a maximum and stable capture of lead. This result agrees with previously reported values of $\mathrm{pH}$ (Ramos et al. 2004; Hamidpour et al. 2011; Kragović et al. 2013b). In the present work, $\mathrm{pH}$ of 5 was selected for the following experiments.

\section{Effect of contact time on lead sorption capacity: study of kinetics of sorption process}

Kinetics of lead sorption from aqueous solutions onto NZ zeolite was studied for 3 to 90 min by using a magnetic shaker. Others parameters fixed in this experiment were $\mathrm{pH}$ of 5 , sorbent mass of $10 \mathrm{mg}$, solution volume of $10 \mathrm{~mL}$, lead concentration of $5 \mathrm{mg} \mathrm{L}^{-1}$ and room temperature.

It is a well-known fact that the sorption of heavy metals on zeolite is a heterogeneous process, which involves various stages (Sprynskyy et al. 2006; Aksu et al. 2008; Sen and Gómez 2011; Malamis and Katsou 2013). In Fig. 4, two principal stages are observed. The first one is a relatively fast intake, corresponding to the first 10 -min contact where around $93 \%$ lead ions present in solution were sorbed. In the second one, only around $3 \%$ more lead

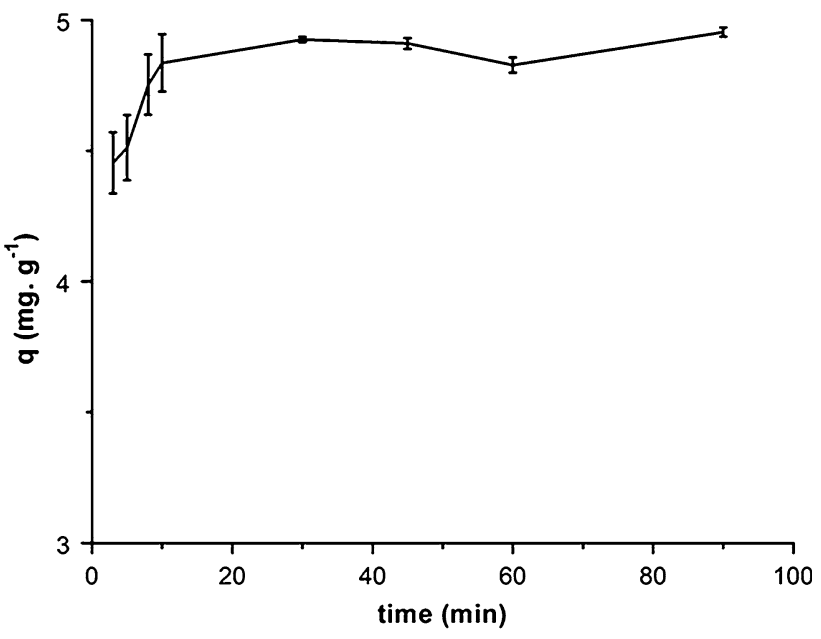

Fig. 4 Influence of contact time on the lead sorption capacity of $\mathrm{NH}_{3}$-treated zeolite

was sorbed on zeolite. This is probably due to the saturation of sorbent surface with lead ions over the first $10 \mathrm{~min}$, followed by sorption and desorption processes that allowed a little more increased sorption of lead. Similar behaviors were observed in previous studies of sorption of lead on zeolites (Sprynskyy et al. 2006, Karatas 2012). According to the obtained results, a contact time of around $30 \mathrm{~min}$ can be selected. Nevertheless, in order to ensure the equilibrium, up to 60-min contact time was used in the present work.

Also, the pseudo-first-order and pseudo-second-order models have been reported in order to describe the kinetics of the solution/solid adsorption systems (Ho 2006; Sprynskyy et al. 2006; Hamidpour et al. 2011; Enamorado et al. 2011; Karatas 2012; Kragović et al. 2013b; Malamis and Katsou 2013). Most reports, including those dealing with the sorption of lead on zeolites, concluded that the pseudosecond-order model fits to the experimental data (Ho 2006; Hamidpour et al. 2011; Enamorado et al. 2011; Kragović et al. 2013b; Malamis and Katsou 2013). In particular, it has been established that adsorption processes can be described by the pseudo-second-order model for any adsorbent/adsorbate system, when the initial concentration of solute is low (Azizian 2004).

Consequently, the adequacy of the pseudo-second-order kinetic model was studied, according to Eq. 4:

$\frac{\mathrm{d} q}{\mathrm{~d} t}=k_{2}\left(q_{\mathrm{e}}-q\right)^{2}$

where $q$ and $q_{\mathrm{e}}$ are the amount of lead sorbed per mass unit of sorbent material $\left(\mathrm{mg} \mathrm{g}^{-1}\right)$ at time $t$ and in equilibrium, respectively; $k_{2}$ is the rate constant of the lead sorption process $\left(\mathrm{g} \mathrm{mg}^{-1} \mathrm{~min}^{-1}\right)$. Integration of Eq. 4 leads to Eq. 5: 
$\frac{t}{q}=\frac{1}{k_{2} \cdot q_{\mathrm{e}}^{2}}+\frac{1}{q_{\mathrm{e}}}$

The model described by Eq. 5 fitted to the experimental data with a correlation coefficient of 0.9996 (Fig. 5). The quality of the fit was evaluated by the lack-of-fit statistical test with a $99 \%$ level of probability. Next,

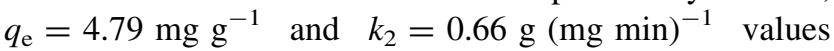
were calculated as the slope and intercept, respectively, of the regression line. The pseudo-second-order kinetic model provided a near-perfect match between the theoretical $q_{\mathrm{e}}=4.79 \mathrm{mg} \mathrm{g}^{-1}$ and experimental $q_{\mathrm{e}}=4.78 \mathrm{mg} \mathrm{g}^{-1}$ sorption capacities under equilibrium conditions. Good correlations of experimental data with the pseudo-second-order kinetic model have also been reported for the sorption of lead on clinoptilolite (Sprynskyy et al. 2006; Hamidpour et al. 2011; Kragović et al. 2013b), natural zeolitic tuff (Karatas 2012) and some other adsorbents (Ho and Ofomaja 2006; Enamorado et al. 2011).

\section{Influence of solid sorbent mass-to-volume solution ratio on lead sorption capacity}

This experiment was performed in two parts with lead mass, $\mathrm{pH}$ and contact time being $50 \mathrm{mg}, 5$ and $30 \mathrm{~min}$, respectively. First, the sorbent mass was changed from 10 to $100 \mathrm{mg}$, with lead solution volume being $10 \mathrm{~mL}$. Second, the solution volume was changed from 10 to $150 \mathrm{~mL}$, with sorbent mass being $10 \mathrm{mg}$.

Variation of lead sorption capacity of $\mathrm{NH}_{3}$-treated $\mathrm{NZ}$ zeolite with solid sorbent mass-to-volume solution ratio is shown in Fig. 6. Two different behaviors are observed. First, when sorbent mass-to-solution volume ratio was changed from 0.06 to $0.1 \mathrm{~g} \mathrm{~L}^{-1}$, a quick increase in lead sorption capacity was observed. This behavior was characterized by a slope of $819 \%$ lead sorbed on zeolite per

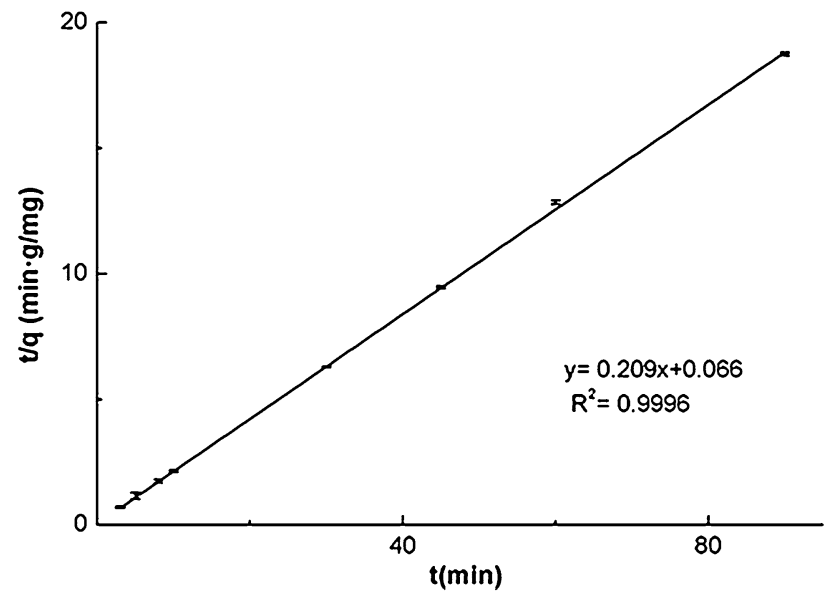

Fig. 5 Linear pseudo-second-order kinetics plot for sorption of lead on $\mathrm{NH}_{3}$-treated zeolite

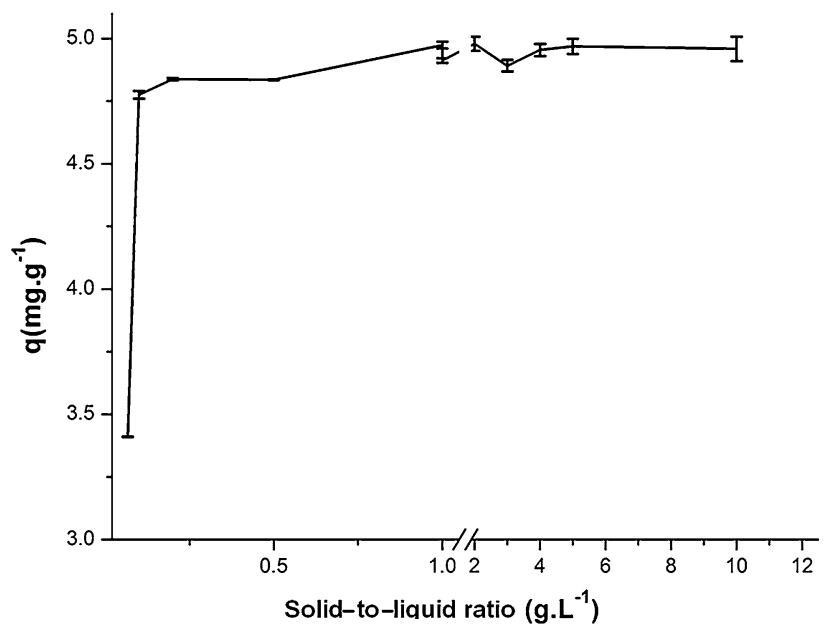

Fig. 6 Influence of sorbent mass-to-water volume ratio on the lead sorption capacity of $\mathrm{NH}_{3}$-treated zeolite

$\mathrm{mg} \mathrm{mL}^{-1}$ of solid-to-liquid ratio. Second, when solid-toliquid ratio ranged from 0.1 to $10 \mathrm{~g} \mathrm{~L}^{-1}$, lead sorption capacity varied little, being practically constant from 1 to $10 \mathrm{~g} \mathrm{~L}^{-1}$. The obtained results could be explained as follows: when sorbent mass-to-solution volume ratio is low $\left(<0.1 \mathrm{~g} \mathrm{~L}^{-1}\right)$, metal ions are more dispersed and therefore diffusion of ions in solution to active sites on zeolite surface is slower. In contrast, the diffusion process is faster for higher solid-to-solution ratios because there are more active sites and they are closer to lead ions. This fact allows a quicker capture of lead ions. Similar results were obtained by other authors in removing lead from aqueous solutions by means of clinoptilolite and bentonite (Hamidpour et al. 2011). For all the range of solid-to-liquid ratio studied, no aggregates of sorbent material were observed.

According to this experiment, an $\mathrm{NH}_{3}$-treated $\mathrm{NZ}$ zeolite mass-to-solution volume ratio ranging from 1 to $10 \mathrm{~g} \mathrm{~L}^{-1}$ can be selected, in order to achieve the highest lead sorption.

\section{Quantification of lead in drinking waters by FAAS after lead concentration on $\mathrm{NH}_{3}$-treated $\mathrm{NZ}$ zeolite}

FAAS is widely used to quantify metals in natural and waste waters. However, the concentration of elements is sometimes under the quantification limits of the technique. Consequently, some other procedures for concentrating lead prior to quantification can be followed. In this context, the combination of lead ion capture by $\mathrm{NH}_{3}$-treated NZ zeolite and quantification of lead in water by FAAS is considered useful, and for that reason, it is studied in the present work, with a commercial drinking water being selected as target sample. 
The presence of lead was not detected, when drinking water (non-doped water in Table 2) was directly analyzed by FAAS without previous concentration. Two portions of samples were doped afterward with 0.05 and $0.1 \mathrm{mg} \mathrm{L}^{-1}$ lead, respectively. These samples are identified as 0.05doped water and 0.1-doped water in Table 2. Both concentrations were selected because the maximum permissible concentration of lead in drinking water is $0.05 \mathrm{mg} \mathrm{L}^{-1}$, according to Cuban Guidelines for Drinking Water Quality (NC 93-02:1997 1997) and others guidelines. See, for example, guidelines of the World Health Organization (WHO 2011). Next, both samples were subjected to a lead concentration process using $\mathrm{NH}_{3}$ treated NZ zeolite under the following conditions: sorbent mass-to-solution volume ratio of $1 \mathrm{~g} \mathrm{~L}^{-1}$ (volume of solution $=100 \mathrm{~mL}$ ), contact time of $60 \mathrm{~min}$ and $\mathrm{pH}$ of 5 . Because sample is required to be in liquid state in order to be analyzed by FAAS, lead sorbed on treated zeolite had to be eluted by means of $10 \mathrm{~mL}$ of $0.1 \mathrm{mo} \mathrm{L}^{-1}$ $\mathrm{HNO}_{3}$ solution. Therefore, two types of solutions were subjected to analysis by FAAS. The first type of solutions was doped drinking waters remained after the sorption process, and the second one was solutions eluted in nitric acid, in which the amount of lead previously sorbed on zeolite could be quantified. Lead was not detected in remaining doped drinking water samples, after they were subjected to sorption process, whereas lead was successfully quantified in solutions eluted in nitric acid. In Table 2, concentrations of lead determined in eluted solutions (found concentration) have been expressed with respect to the concentration of lead in initially doped drinking waters. In this way, it was possible to compare the determined (found) concentrations of lead in eluted solutions with the doped concentration (expected concentration in Table 2). As it can be seen, the recovery of lead is 107 and $111 \%$ for 0.05 and $0.1 \mathrm{mg} \mathrm{L}^{-1}$, respectively. It means that after a previous concentration of lead present in doped drinking water (volume of $100 \mathrm{~mL}$ ) on treated NZ zeolite and elution in nitric acid, the originally doped concentration in drinking water was determined with an accuracy of around $10 \%$. The precision of analysis, given as relative standard deviation, was 15 and $2.8 \%$. The obtained results demonstrated that the combination of lead ions capture by $\mathrm{NH}_{3}$-treated $\mathrm{NZ}$ zeolite and quantification of lead in water by FAAS was useful indeed, which made the quantification of a low concentration of $0.05 \mathrm{mg} \mathrm{L}^{-1}$ possible. Without pre-concentration, this amount of lead could not be determined directly in drinking water by FAAS.

\section{Lead sorption experiments by using PIXE and XRF}

PIXE and XRF are nondestructive techniques. This feature has the great advantage of reusing samples for other purposes.

These experiments of $\mathrm{Pb}$ sorption were performed on non-treated and $\mathrm{NH}_{3}$-treated zeolites with $\mathrm{pH}$ of 5 , solid-toliquid ratio of $4 \mathrm{~g} \mathrm{~L}^{-1}$ and contact time of $30 \mathrm{~min}$. Initial concentrations of lead in target solution samples were 10 and $20 \mu \mathrm{g} \mathrm{mL}^{-1}$, which are equivalent to 0.25 and $0.5 \%$ $\mathrm{w} / \mathrm{w} \mathrm{Pb}$ concentration, respectively, in zeolite, assuming that $100 \%$ metal in solution would be captured. For each target solution, the above sorption procedure was repeated three times, as well as for a blank sample (non-doped water) used in each experiment. Once the sorption was over, both the solid sorbent and solution phases were separated by decantation process and zeolite dried at $60{ }^{\circ} \mathrm{C}$. The addition of $\sim 1 \mathrm{~mL}$ of $5 \% \mathrm{w} / \mathrm{v}$ polyvinyl ethanol dissolved in double-distilled water to zeolite was necessary to obtain an adequate compact pellet. Finally, the mixture was dried in a furnace at $30{ }^{\circ} \mathrm{C}$ for few minutes, and 12-mm-diameter pellets were obtained by applying $9 \mathrm{t} \mathrm{cm}^{-2}$ pressure for $5 \mathrm{~min}$. In this way, a total of fourteen 12-mm-diameter pellet samples were prepared.

$\mathrm{Pb}$ content in solid (sorbent) samples as a result of the sorption process was determined by using the PIXE technique. A $2 \mathrm{MeV}$ proton beam provided by the $3 \mathrm{MV}$ Tandetron accelerator of the Implantation Laboratory of the Universidade Federal do Rio Grande do Sul was used. The mean proton current was around $0.5 \mathrm{nA}$. The X-rays induced by the proton bombardment on the sample were detected by a $\mathrm{Si}(\mathrm{Li})$ detector, with it having an overall resolution higher than $150 \mathrm{eV}$ for a $5.9 \mathrm{keV}$ of the $\mathrm{K} \alpha$ line of Fe. The X-ray peak employed for the determination of lead was $\mathrm{L}_{\beta} 10.551 \mathrm{keV}$. Two typical PIXE spectra corresponding to (a) blank sample, namely $\mathrm{NH}_{3}$-treated $\mathrm{NZ}$ Zeolite and (b) $\mathrm{NH}_{3}$-treated $\mathrm{NZ}$ Zeolite after the lead sorption, are shown in Fig. 7.
Table 2 Precision and accuracy of determination of lead in drinking water by FAAS after concentration by sorption on $\mathrm{NH}_{3}$-treated $\mathrm{NZ}$ zeolite

\begin{tabular}{lllll}
\hline Sample & $\begin{array}{l}\text { Doped concentration } \\
\left(\mathrm{mg} \mathrm{L}^{-1}\right)\end{array}$ & $\begin{array}{l}\text { Found concentration } \\
\left(\mathrm{mg} \mathrm{L}^{-1}\right)\end{array}$ & $\begin{array}{l}\text { Precision } \\
(\%)\end{array}$ & $\begin{array}{l}\text { Recovery } \\
(\%)\end{array}$ \\
\hline Non-doped water & - & Not detected & - & - \\
0.05-doped water & 0.05 & $0.053 \pm 0.008$ & 15 & 107 \\
0.1 -doped water & 0.1 & $0.111 \pm 0.003$ & 2.8 & 111 \\
\hline
\end{tabular}

Precision is given as relative standard deviation and accuracy as recovered concentration in percentage 
For standardization, the protocol by Johansson et al. was used (Johansson et al. 1995). In order to quantify lead from spectra obtained by PIXE, the software GUPIXWIN version 2.2 (Maxwell et al. 1995, Campbell et al. 2000) was used. This code initially adjusts the peaks that appear in the spectra by using the minimum square method and then converts the peak intensities in concentrations of the corresponding elements.

In addition to PIXE, a more worldwide used XRF was employed as well. In this case, an energy-dispersive X-ray spectrometer (Shimadzu, Ray ny EDX-800 HS) equipped with an $\mathrm{Rh}$ lamp and a $10-\mathrm{mm}$ collimator operating at $50 \mathrm{kV}, 100 \mathrm{~mA}$ was used. This technique is based on the same physical principles as PIXE. However, the quantification procedure and data analysis are completely different. In fact, several powder calibration standards with lead concentrations ranging from 0.1 to $1.5 \% \mathrm{w} / \mathrm{w}$ were prepared by mixing appropriate amounts of $\mathrm{PbO}$ reagent (Specpure, JMC, England) and zeolite in an agate mortar. The corresponding tablets of around $15 \mathrm{~mm}$ of diameter were prepared afterward. The net area under the curve was used as analytical signal.

The results obtained by PIXE and XRF are displayed in Table 3. It is worth noting that no lead signal was detected in either of the blank samples prepared with NZ zeolite and $\mathrm{NH}_{3}$-treated $\mathrm{NZ}$ zeolite, respectively, used as sorbent materials. Therefore, no correction for background signal was needed.

A Student's $t$ test for 95 or $99 \%$ confidence levels and $n-1=2 d f$ was then applied in order to compare the lead-determined concentration (PIXE and XRF concentrations in columns 3 and 6, respectively, in Table 3) and the expected lead concentration of 0.25 and $0.50 \%$ in sorbent material (column 2 in Table 3). Experimental $t$ value was
Fig. 7 Typical PIXE spectra of $\mathrm{NH}_{3}$-treated zeolite before

(a) and after (b) sorption of $0.5 \%$ lead
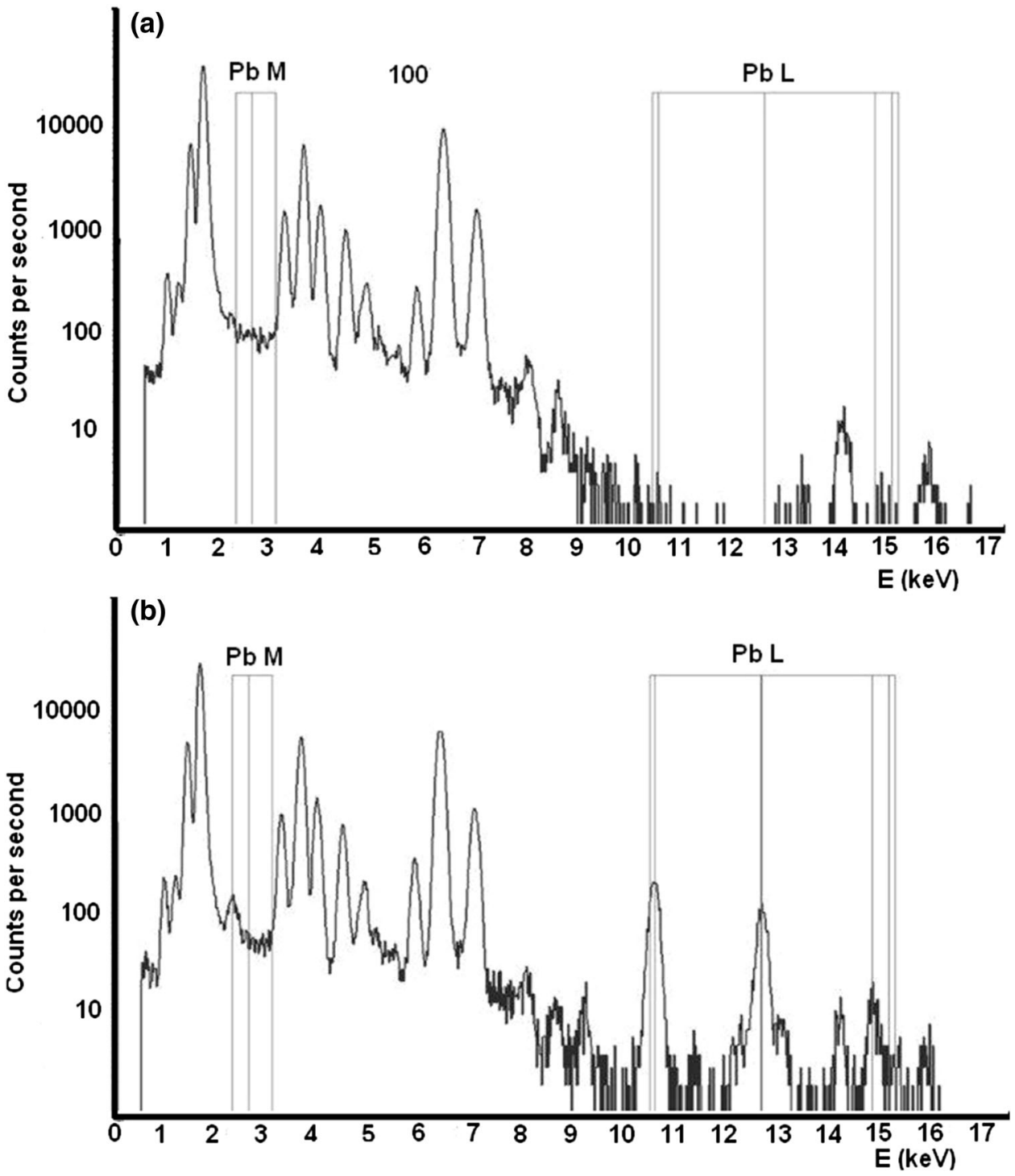
Table 3 Particle-induced X-ray emission and X-ray fluorescence determination of lead concentration in NZ zeolite and $\mathrm{NH}_{3}$-treated $\mathrm{NZ}_{\text {zeolite }}$

\begin{tabular}{|c|c|c|c|c|c|c|c|}
\hline \multirow[t]{2}{*}{ Sample } & \multirow{2}{*}{$\begin{array}{l}\text { Expected } \\
\text { concentration } \\
(\%)\end{array}$} & \multicolumn{3}{|c|}{ Particle-induced X-ray emission } & \multicolumn{3}{|l|}{$\mathrm{X}$-ray fluorescence } \\
\hline & & $\begin{array}{l}\text { Determined } \\
\text { concentration } \pm \text { standard } \\
\text { deviation }^{\mathrm{a}}(\%)\end{array}$ & $\begin{array}{l}\text { Precision } \\
(\%)\end{array}$ & $\begin{array}{l}\text { Recovery } \\
(\%)\end{array}$ & $\begin{array}{l}\text { Determined } \\
\text { concentration } \pm \text { standard } \\
\text { deviation }^{\mathrm{a}}(\%)\end{array}$ & $\begin{array}{l}\text { Precision } \\
(\%)\end{array}$ & $\begin{array}{l}\text { Recovery } \\
(\%)\end{array}$ \\
\hline $\begin{array}{l}\text { NZ zeolite } \\
\text { blank }\end{array}$ & Non-doped & Not detected & - & - & Not detected & - & - \\
\hline $\begin{array}{r}0.25-\mathrm{NZ} \\
\text { zeolite }\end{array}$ & 0.25 & $0.28 \pm 0.02(2.59)$ & 7.14 & 112.0 & $0.23 \pm 0.01(3.46)$ & 4.34 & 92.0 \\
\hline $\begin{array}{r}0.50-\mathrm{NZ} \\
\text { zeolite }\end{array}$ & 0.50 & $0.489 \pm 0.008$ & 1.64 & 97.8 & $0.50 \pm 0.01(0)$ & 2.0 & 100.0 \\
\hline $\begin{array}{l}\mathrm{NH}_{3} \text {-treated } \\
\mathrm{NZ} \text { zeolite } \\
\text { blank }\end{array}$ & Non-doped & Not detected & - & - & Not detected & - & - \\
\hline $\begin{array}{l}0.25-\mathrm{NH}_{3}- \\
\text { treated } \mathrm{NZ} \\
\text { zeolite }\end{array}$ & 0.25 & $0.233 \pm 0.003(9.82)^{\mathrm{b}}$ & 1.29 & 93.2 & $0.242 \pm 0.004$ & 1.65 & 96.8 \\
\hline $\begin{array}{l}0.5-\mathrm{NH}_{3}- \\
\quad \text { treated } \mathrm{NZ} \\
\text { zeolite }\end{array}$ & 0.50 & $0.45 \pm 0.01(8.66)^{\mathrm{b}}$ & 2.22 & 90.0 & $0.50 \pm 0.01(0)$ & 2.0 & 100.0 \\
\hline
\end{tabular}

$t$ values from statistical table were 4.303 and 9.925 for 95 and $99 \%$ confidence levels, respectively

a Experimental value of Student's $t$ test parameter is added in parenthesis along determined concentrations; ${ }^{\mathrm{b}} t$ experimental values were compared with $t$ from table for $99 \%$ confidence level. The rest of $t$ experimental values were compared with $t$ from table for $95 \%$ confidence level

always lower than $t$ value from table ( $t$ table was 4.303 and 9.925 for 95 and $99 \%$ confidence levels, respectively), which demonstrated that determined and expected concentrations were similar within the experimental error in all cases.

The percent recovery varied satisfactorily between 90 and $112 \%$, whereas precision error of the analysis was lower than $10 \%$ for both concentrations and sorbent materials used in present experiments. These features can be considered good enough in view of the concentration process of lead on zeolitic material prior to instrumental quantification.

Both applied analytical techniques, PIXE and XRF, were successfully used for the direct determination of lead in $\mathrm{NZ}$ zeolite and $\mathrm{NH}_{3}$-treated zeolite, with there being no need for chemical digestion of samples. Besides, the use of $\mathrm{NH}_{3}$-treated zeolite in order to concentrate lead is certainly a promising simple procedure to improve the determination of lead in water by FAAS.

\section{Conclusion}

The obtained results confirmed that Cuban clinoptilolitetype zeolite from the deposit Tasajeras exhibits great potential as sorbent material in order to concentrate $\mathrm{Pb}$ (II) from water.
It was shown that for water contaminated by lead concentrations lower than $10 \mathrm{mg} \mathrm{L}^{-1}$, no treatment of zeolite is required, whereas for concentrations higher than $10 \mathrm{mg}$ $\mathrm{L}^{-1}$, the use of $\mathrm{NH}_{3}$-treated zeolite is suggested because its capacity to sorb lead is the highest for these higher lead concentrations. In this case, special attention should be paid to the reproducibility of sorption processes and its control.

The potential of PIXE and XRF techniques has been successfully demonstrated as compatible detection techniques for monitoring the concentration of lead in drinking waters by determining, directly, lead concentration sorbed on zeolite with no need of sample chemical digestion neither elution of sorbed lead on zeolite. In addition, the quantification of lower concentrations of lead in drinking waters by the more traditional FAAS technique was improved as well.

Acknowledgments The present work was carried out within the framework of the Project "Increase of the Reliability in the Quantification of Metals in Environmental Samples and Advanced Materials," implemented by the IMRE of the University of Havana. Besides, this work is part of the International Project "Analysis of Materials by Using Analytical Techniques Based on Ions Beams and Optical Spectrometry," No. 121/11, engaged in by the Coordenação de Aperfeiçoamento de Pessoal de Nível Superior (CAPES, according to its abbreviation in Portuguese) from Brazil, through the Ion Implantation Laboratory of the Universidade Federal do Rio Grande do Sul, and the Cuban Ministry of Higher Education, through IMRE. 
The authors would like to thank Nestor Laria Ruiz for his useful advises.

\section{References}

Aksu Z, Tatli AI, Tunc O (2008) A comparative adsorption/ biosorption study of Acid Blue 161: effect of temperature on equilibrium and kinetic parameters. J Chem Eng 142:23-39

Alfaro de la Torre M, Tessier A (1993) Adsorption of Arsenic, Copper and Lead on components of natural oxidized aquatic sediments. Adsorption models applicability. In: Proceedings of the IX National Congress AIDIS. 11-31 to 11-37

Azizian S (2004) Kinetic models of sorption: a theoretical analysis. J Colloid Interface Sci 276:47-52

Babel S, Kurniawan TA (2003) Low-cost adsorbents for heavy metals uptake from contaminated water: a review. J Hazard Mater B97:219-243

Baerlocher Ch, Olson DH, Meier WM (2001) Atlas of zeolites framework types, 5th edn. Elsevier, Amsterdam

Bailey SE, Olin TJ, Bricka M, Adrian DD (1999) A review of potentially low-cost sorbents for heavy metals. Water Res 33:2469-2479

Boza A, Jiménez J, Cortés I (2001) Determination of major and minor elements in Cuban zeolites using X-ray fluorescence. Rev CENIC Cienc Quím 32:7-11

Campbell JL, Hopman TL, Maxwell JA, Nejedly Z (2000) The Guelph PIXE software package III: alternative proton database. Nucl Instrum Methods Phys Res B 170:193-204

Castaldi P, Santona L, St Enzo, Melis P (2008) Sorption processes and XRD analysis of a natural zeolite exchanged with $\mathrm{Pb}^{2+}$, $\mathrm{Cd}^{2+}$ and $\mathrm{Zn}^{2+}$ cations. J Hazard Mater 156:428-434

Daar E, Al Mugren KS, Chika S, Barnes S, Bradley DA (2015) XRF measurements of $\mathrm{Zn}, \mathrm{Sr}$ and $\mathrm{Pb}$ in archaeological bone. X-Ray Spectrom 44:129-134. doi:10.1002/xrs.2589

Draper NR, Smith H (1981) Applied regression analysis. Wiley, New York

Enamorado Y, Villanueva M, Hernández I, Coto O, Pomares M (2011) Characterization of inactive biomass of Aspergillus niger O5 as sorbent for $\mathrm{Pb}(\mathrm{II})$. Quim Nova 34:141-1146

Freundlich HMF (1906) Over the adsorption in solution. J Phys Chem 57:e470

Ghosh M, Swain KK, Chavan TA, Wagh DN, Verma R (2015) Determination of gold and silver in dross using EDXRF technique. X-Ray Spectrom 44:13-15. doi:10.1002/xrs.2571

Goldberg S (2005) Equations and models describing adsorption processes in soils. In: Tabatabai MA, Sparks DL, Al-Amoodi L, Dick WA (eds) Chemical processes in soils. Soil Science Society of America Inc, Madison, pp 489-517

González ME, Mattusch M, Wennrich R (2001) Application of natural zeolites for preconcentration of arsenic species in water samples. J Environ Monit 3:22-26

Granados SR, Correa FG, Becerril JJ (2000) Retention of phenol in aqueous solution over activated carbon and zeolite X. Rev Int Contam Ambient 16:37-40

Granda M, Pérez AI, Díaz ME (2006) Zeolites and zeolite-based materials in analytical chemistry. TrAC Trends Anal Chem 25:24-30

Hamidpour M, Kalbasi M, Afyuni M, Shariatmadari H, Furrer G (2011) Sorption of lead on Iranian bentonite and zeolite: kinetics and isotherms. Environ Earth Sci 62:559-568

Hernández García R, Behar M, Ferraz Dias J, Villanueva Tagle ME, Durruthy Rodríguez MD, Calderón Piñar F, Pomares Alfonso MS (2012) Determination of $\mathrm{Pb}, \mathrm{Zr}, \mathrm{Ti}, \mathrm{Sr}, \mathrm{Cr}, \mathrm{Nb}$ and $\mathrm{La}$ in lead zirconate-titanate ceramics by particle induced X-ray emission. X-Ray Spectrom 41:156-163

Ho YS (2006) Review of second-order models for adsorption systems. J Hazard Mater B 136:681-689

Ho YS, Ofomaja AE (2006) Pseudo-second-order model for lead ion sorption from aqueous solutions onto palm kernel fiber. J Hazard Mater B129:137-142

Inglezakis VJ, Diamandis NA, Loizidou MD, Grigoropoulou HP (1999) Effect of pore clogging on kinetics of lead uptake by clinoptilolite. J Colloid Interface Sci 215:54-57

Inglezakis VJ, Papadeas CD, Loizidou MD, Grigoropoulou HP (2001) Effects of pretreatment on physical and ion exchange properties of natural clinoptilolite. Environ Technol 22:75-82

Inglezakis VJ, Loizidou MD, Grigoropoulou HP (2002) Equilibrium and kinetic ion exchange studies of $\mathrm{Pb}^{2+}, \mathrm{Cr}^{3+}, \mathrm{Fe}^{3+}$ and $\mathrm{Cu}^{2+}$ on natural clinoptilolite. Water Res 36:2784-2792

Inglezakis VJ, Loizidou MD, Grigoropoulou HP (2003) Ion exchange of $\mathrm{Pb}^{2+}, \mathrm{Cu}^{2+}, \mathrm{Fe}^{3+}$, and $\mathrm{Cr}^{3+}$ on natural clinoptilolite: selectivity determination and influence of acidity on metal uptake. J Colloid Interface Sci 261:49-54

Inglezakis VJ, Loizidou MM, Grigoropoulou HP (2004) Ion exchange studies on natural and modified zeolites and the concept of exchange site accessibility. J Colloid Interface Sci 275:570-576

Inglezakis VJ, Stylianou MA, Gkantzou D, Loizidou MD (2007) Removal of $\mathrm{Pb}(\mathrm{II})$ from aqueous solutions by using clinoptilolite and bentonite as adsorbents. Desalination 210:248-256

Johansson SA, Campbell JL, Malmqvist KG (1995) Particle-induced X-ray emission spectrometry (PIXE), 1st edn. Wiley, New York

Karatas M (2012) Removal of Pb(II) from water by natural zeolitic tuff: kinetics and thermodynamics. J Hazard Mater 199-200:383-389

Kolbe M, Hönicke P (2015) Fundamental parameters of Zr and Ti for a reliable quantitative $\mathrm{X}$-ray fluorescence analysis. X-Ray Spectrom 44:217-220. doi:10.1002/xrs.2603

Kragovic M, Dakovic A, Sekulic Z, Trgo M, Ugrina M, Peric J, Gatta GD (2012) Removal of lead from aqueous solutions by using the natural and $\mathrm{Fe}(\mathrm{III})$-modified zeolite. Appl Surf Sci 258:3667-3673

Kragović M, Daković A, Marija M, Sekulić Ž (2013a) Kinetic of sorption of lead on natural and iron(III)-modified zeolite. In: Proceedings of the 5th Serbian-Croatian-Slovenian symposium on zeolites. pp 124-127. http://www.zds.org.rs/doc/Proc_124127.pdf. Accessed 9 Oct 2015

Kragović M, Daković A, Marković M, Krstić J, Diego Gatta G, Rotirotica N (2013b) Characterization of lead sorption by the natural and Fe(III)-modified zeolite. Appl Surf Sci 283:764-774

Malamis S, Katsou E (2013) A review on zinc and nickel adsorption on natural and modified zeolite, bentonite and vermiculite: examination of process parameters, kinetics and isotherms. J Hazard Mater 252-253:428-461

Maxwell JA, Teesdale WJ, Campbell JL (1995) The Guelph PIXE software package II. Nucl Instrum Methods Phys Res B 95:407-421

Misaelides P (2011) Application of natural zeolites in environmental remediation: a short review. Microporous Mesoporous Mater 144:15-18

NC 93-02:1997 (1997) Anteproyecto de Norma Cubana. Agua potable. http://www.bvsde.paho.org/bvsacg/e/normas2/NormaCub.pdf. Accessed 22 Feb 2016

Pérez AI, Granda M, Torres JC, Pina G, García JA, Díaz ME (2008) Characterization of the binding site affinity distribution of a surfactant-modified clinoptilolita. Microporous Mesoporous Mater 109:38-48

Pillay A, Peisach M (1991) Zeolite Analysis: PIXE, XRF or Neutron Activation. J Radioanal Nucl Chem 153:75-84 
Pillay AE, Peisach M, Carolissen R, Pineda CA (1990) PIXE determination of silicon/aluminum ratios in zeolites and geological materials. Nucl Instrum Methods Phys Res B 45:333-336

Ponizovskya AA, Tsadilas CD (2003) Lead(II) retention by Alfisol and clinoptilolite: cation balance and $\mathrm{pH}$ effect. Geoderma 115:303-312

Ramos RL, Mendoza MSB, Barrón JM, Piña AA (2004) Intercambio iónico de $\mathrm{Pb}(\mathrm{II})$ en solución acuosa sobre clinoptilolita modificada por intercambio catiónico. Rev Soc Quím Méx 48:130-136

Rodríguez Fuentes G, Torres JC, Mora E, Vega N (2000) Solicitud de patente cubana No. 2000-0221

Rodríguez G, Salvador R, Mir M, Picazo O, Quintana G, Delgado M (1998) Thermal and cation influence on IR vibrations of modified natural clinoptilolite. Microporous Mesoporous Mater 20:269-281

Rodríguez G, Ávila P, Rodríguez I, Rebollar M, Betancourt M, Concepción B, Bogdanchikova N (2004) Environmental remediation uses of honeycomb monoliths based on natural clinoptilolite. Stud Surf Sci Catal 154C:2555-2559

Sen TK, Gómez D (2011) Adsorption of zinc $\left(\mathrm{Zn}^{2+}\right)$ from aqueous solution on natural bentonite. Desalination 267:286-294
Sirotiak M, Lipovsky M, Bartosova (2015) A sorption kinetics of selected heavy metals adsorption to natural and Fe(III) modified zeolite tuff containing clinoptilolite mineral. Res pap Fac Mater Sci Technol Slovak Univ Technol 23:41-47. http://www.mtf. stuba.sk/docs/doc/casopis_Vedecke_prace/36/10_sirotiak_ lipovsky_bartosova.pdf. Accessed 9 Oct 2015

Sprynskyy M, Buszewski B, Terzyk AP, Namiesnik J (2006) Study of the selection mechanism of heavy metal $\left(\mathrm{Pb}^{2+}, \mathrm{Cu}^{2+}, \mathrm{Ni}^{2+}\right.$, and $\mathrm{Cd}^{2+}$ ) adsorption on clinoptilolite. J Colloid Interface Sci 304:21-28

Wang Sh, Peng Y (2010) Natural zeolites as effective adsorbents in water and wastewater treatment. Chem Eng J 156:11-24

Willis JP (1988) XRFS AND PIXE: are they complementary or competitive techniques? A critical comparison. Nucl Instrum Methods Phys Res B 35:378-387

World Health Organization (2011) Guidelines for drinking water quality, 4th edn. ISBN 978924154815 1. http://www.who.int/ 